\title{
Avaliação de Danos Causados pelo Barley yellow dwarf virus - PAV em Cultivares de Trigo no Brasil
}

\author{
Ariane C. Lanzarini ${ }^{1}$, Jurema Schons ${ }^{1}$, José R. Salvadori ${ }^{2}$, Alexandre A. Nienow ${ }^{1}$, \\ Fernanda Nicolini-Teixeira ${ }^{1}$, Francini Binotto-Missiura ${ }^{1} \&$ Elaine Deuner ${ }^{1}$
}

${ }^{1}$ Faculdade de Agronomia e Medicina Veterinária, Universidade de Passo Fundo, Cx. Postal 611; ${ }^{2}$ Embrapa Trigo, Cx. Postal 451, CEP 99001-970, Passo Fundo, RS, Brasil, e-mail: schons@upf.br

Autor para correspondência: Jurema Schons

LANZARINI, A.C., SCHONS, J., SALVADORI, J.R., NIENOW, A.A., NICOLINI-TEIXEIRA, F., BINOTTO-MISSIURA, F. \& DEUNER, E. Avaliação de danos causados pelo Barley yellow dwarf virus - PAV em cultivares de trigo no Brasil. Fitopatologia Brasileira 32:512-517. 2007.

\section{RESUMO}

Com o objetivo de avaliar os danos causados pelo Barley yellow dwarf virus - PAV (BYDV-PAV), em cinco cultivares de trigo (BRS 177, BRS 179, BRS 194, BRS Camboatá e BRS Angico), foi conduzido um experimento no telado da Embrapa-Trigo (Passo Fundo RS) no ano de 2005. Os danos induzidos pelo BYDV-PAV foram determinados por meio de análise de características agronômicas (estatura das plantas e massa de matéria seca) e do rendimento (número de afilhos, espigas e grãos por planta; massa de mil grãos). Os dados foram submetidos à análise de variância e as médias ao teste de Tukey a 5\%. Danos significativos em função da infecção viral foram observados em todas as variáveis avaliadas. A característica agronômica mais afetada foi a massa de matéria seca, que variou de 26,1\% (BRS 177) a 51,4\% (BRS 179). Para estatura de plantas foram observadas reduções de 12,5\% (BRS 177) a 15,5\% (BRS Camboatá). O rendimento total de grãos foi o mais afetado pela infecção viral, sendo que, danos significativos foram observados em todas as cultivares, cuja redução variou de 34,2\% (BRS Camboatá) a 60,8\% (BRS 179). No número médio de afilhos por planta, apenas as cultivares BRS Angico e BRS 179 apresentaram reduções de $20 \%$ e 26,6\%, respectivamente. A redução do número médio de grãos variou de 26,1\% (BRS Camboatá) a 54,3\% (BRS 179). Também ocorreu diminuição no peso de mil grãos com redução que variou de $16,9 \%$ (BRS Camboatá) a 38,4\% (BRS 194).

Palavras-chave adicionais: Luteovírus, afídeos, Triticum aestivum.

\begin{abstract}
Assessment of damage caused by the Barley yellow dwarf virus in Brazilian wheat cultivars

The aim of this study was to assess the damage caused by the Barley yellow dwarf virus (BYDV-PAV) in five wheat cultivars (BRS 177, BRS 179, BRS 194, BRS Camboatá and BRS Angico) grown in a greenhouse at Embrapa (Empresa Brasileira de Pesquisa Agropecuária), Passo Fundo, state of Rio Grande do Sul, Brazil, in 2005. The damage caused by the BYDV-PAV was determined by the analysis of agronomic traits (plant height and dry matter) and yield (number of tillers, ears, and grains per plant; thousand-grain weight). The data were submitted to the analysis of variance and the means were determined by Tukey's test at 5\%. The virus significantly affected all of the tested variables. Among the agronomic traits, dry matter was the most affected one, with rates between $26.1 \%$ (BRS 177) and $51.4 \%$ (BRS 179). Reductions in plant height ranged between $12.5 \%$ (BRS 177) and 15.5\% (BRS Camboatá). Total grain yield was greatly affected by the viral infection, with significant damage in all cultivars, with a reduction between 34.2\% (BRS Camboatá) and 60.8\% (BRS 179). There was a reduction in the mean number of tillers per plant only in BRS Angico and BRS 179 cultivars, which amounted to $20 \%$ and $26.6 \%$ respectively. The reduction in the mean number of grains varied between $26.1 \%$ (BRS Camboatá) and $54.3 \%$ (BRS 179). Finally, the reduction in thousand-grain weight corresponded to $16.9 \%$ and $38.4 \%$ in BRS Camboatá and BRS 194 cultivars, respectively.
\end{abstract}

Additional keywords: Luteovirus, aphids, Triticum aestivum.

O trigo (Triticum aestivum L.) está sujeito a diversas doenças, entre as quais se destacam, por sua importância econômica, a ferrugem da folha, a ferrugem do colmo, manchas foliares e a virose do nanismo amarelo da cevada, causada pelo Barley yellow dwarf virus (BYDV) (Burnett et al., 1995).

O BYDV causa a enfermidade viral mais disseminada

Parte da Dissertação de Mestrado do primeiro autor. Universidade de Passo Fundo. Passo Fundo RS. 2006. em cereais de inverno em todo o mundo. Ocorre em toda a América do Norte, na Europa, na Ásia, na América do Sul, na Austrália e na Nova Zelândia (Lister \& Ranieri, 1995). O vírus é transmitido de maneira persistente circulativa por 23 espécies de pulgões e infecta aproximadamente 100 espécies de gramíneas anuais e perenes, incluindo cevada, milho, aveia, arroz e trigo, ficando restrito aos tecidos do floema das plantas infectadas (Gray, 1996).

O BYDV caracteriza-se por possuir partícula isométrica com $25 \mathrm{~nm}$ de diâmetro, RNA de fita simples 
(ssRNA), monopartido e senso positivo (Miller \& Rosachova, 1997). Está classificado em várias espécies, sendo que predomina na região sul do Brasil o BYDV-PAV, seguido de BYDV-MAV (Schons \& Dalbosco, 1999), ambos pertencentes à família Luteoviridae, gênero Luteovirus (Van Regenmortel et al., 2000). A designação PAV e MAV está relacionada ao vetor preferencial, assim PAV é preferencialmente transmitido por Rhopalosiphum padi (L.) e MAV por Sitobion avenae (Fabricius), classificado anteriormente como Macrosiphum avenae (F.) (Power et al., 1991).

O BYDV não é transmitido pela semente, pelo solo ou por meios mecânicos. Sua disseminação ocorre unicamente por meio de pulgões. Muitas espécies da família Aphididae podem transmitir o BYDV, Metopolophium dirhodum (Walker), Rhopalosiphum maidis (Fitch), Rhopalosiphum padi (L.), Schizaphis graminum (Rondani) e Sitobion avenae (Fabricius) (Power et al., 1991).

Epidemias do BYDV são irregulares no tempo e espaço, sendo que o vírus pode ocorrer em um determinado ano em uma área e não ocorrer em uma área imediatamente adjacente, e pode subseqüentemente, não ocorrer por vários anos. Os danos, entretanto, podem ser severos em algumas regiões que são afetadas todos os anos. A infecção natural por BYDV em aveia pode causar decréscimo na produtividade que varia de 3 a 52\% (Schons et al., 1999) e em trigo, foram observadas em 1999 reduções na produtividade de até $63 \%$ (Schons et al., 2000).

No caso do BYDV, os danos em plantas infectadas estão relacionados principalmente com o nanismo da planta, a diminuição do tamanho das espigas e diminuição do número de grãos. As alterações no crescimento e nos teores de clorofila refletem-se nas mudanças da anatomia, citologia e fisiologia das plantas infectadas pelo BYDV (Jensen \& D’Arcy, 1995).

O objetivo do presente trabalho foi avaliar os danos causados pelo BYDV-PAV em diferentes cultivares de trigo, inoculadas com o vírus, por três espécies de pulgões, concomitantemente.

O experimento foi conduzido em condições de telado, distribuído em canteiros, na Empresa Brasileira de Pesquisa Agropecuária - Embrapa Trigo, durante o ano de 2005, e as análises foram realizadas no Laboratório de Virologia Vegetal da Faculdade de Agronomia e Medicina Veterinária da Universidade de Passo Fundo e no Laboratório de Entomologia Agrícola da Embrapa Trigo. Foram utilizadas plantas das seguintes cultivares de trigo: BRS 177, BRS 179, BRS 194, BRS Camboatá e BRS Angico. A escolha das cultivares foi em função da indicação que têm recebido da Comissão Sul-Brasileira de Pesquisa de trigo e também, por serem cultivares preferenciais para o plantio na região sul do Brasil. Na semeadura, foram distribuídas 60 sementes por linha e a adubação foi efetuada com $250 \mathrm{~kg} /$ ha da fórmula NPK 5:25:25. A adubação de cobertura foi realizada 30 dias após a emergência e constou de $40 \mathrm{~kg} / \mathrm{ha}$ de $\mathrm{N}$, na forma de uréia. Os tratamentos fitossanitários foram realizados de acordo com o recomendado para a cultura (Reunião...,2005).

Para a inoculação do BYDV foram criadas colônias de pulgões das espécies $R$. padi, S. avenae e S. graminum. As colônias foram multiplicadas em plantas de trigo sadias e posteriormente transferidas para plantas de aveia infectadas com BYDV-PAV para aquisição do vírus. Cada colônia de pulgões foi multiplicada em gaiolas entomológicas individuais contendo cerca de cinco vasos com plantas de aveia infectadas com BYDV, confirmado por DASELISA (Double Antibody Sandwich - Enzyme-Linked Immunosorbent Assay), com leitura da Absorbância (405 $\mathrm{nm}$ ), sem diferenças significativas entre os três grupos de plantas.

Para realização do DAS-ELISA foi utilizado antisoro monoclonal, específico para cada espécie do BYDV, da Agdia Inc. (Elkhart-in-USA) e com leitura da Absorbância (405 nm) em espectrofotômetro (Anthos - Modelo 2010), seguindo a metodologia descrita por Clark \& Adams (1977). Utilizou-se $100 \mathrm{mg}$ de tecido foliar e, $500 \mathrm{mg}$ de pulgões, os quais foram macerados utilizando-se tampão de extração (na proporção de $100 \mathrm{mg} / \mathrm{mL}$ e $500 \mathrm{mg} / 2,5 \mathrm{~mL}$, respectivamente, a fim de confirmar a presença do vírus).

Após o período de aquisição do vírus (sete dias) e doze dias após a emergência das plantas, foram transferidos nove pulgões para cada planta, sendo três de cada espécie. Para a transferência dos pulgões, três fragmentos de folhas com cerca de $1 \mathrm{~cm}^{2}$, contendo três pulgões, cada fragmento com uma espécie de pulgão, foram depositados sobre as plantas sadias, nas quais permaneceram por 10 dias. Os tratamentos foram realizados em sub-parcelas, isoladas por gaiolas entomológicas, de maneira a não haver migração dos pulgões de uma sub-parcela para a outra. Uma sub-parcela permaneceu sem pulgões como controle sadio, embora, também tenha sido protegida por gaiola a fim de evitar diferenças nas condições experimentais. Os pulgões foram eliminados por aspersão com inseticida a base de pirimicarbe (75 g i.a./ha). As gaiolas, de todas as sub-parcelas, foram removidas 24 horas após a aplicação do inseticida.

Aos 50 dias após a inoculação, folhas com sintomas do BYDV foram coletadas de cada cultivar e de cada subparcela para a realização do DAS-ELISA utilizando-se antisoros específicos para BYDV-PAV e MAV. No final do ciclo da cultura, 50 plantas por sub-parcela foram coletadas, a partir das quais foram determinados os danos causados pelo BYDV-PAV sobre as características agronômicas (estatura das plantas e peso de massa seca (parte aérea + raiz)) e de rendimento por seus componentes (número de afilhos e número de espigas; número de grãos por planta e massa de mil grãos).

O delineamento experimental foi em blocos casualizados com seis repetições. Cada repetição constituiuse de cinco linhas ( 5 cultivares) de $0,90 \mathrm{~m}$ de comprimento com espaçamento de $0,2 \mathrm{~m}$ entre linhas sendo que cada cultivar constituiu uma parcela, que foi subdividida em duas sub-parcelas sendo uma infestada com os pulgões 
virulíferos, misturados de três espécies (R. padi, S. avenae, $S$. graminum) e uma sub-parcela isenta de pulgões, como controle sadio. Cada sub-parcela com 50 plantas representava uma repetição.

Ao iniciar o trabalho, conforme consta da metodologia, foram avaliados por DAS-ELISA os pulgões e as plantas fontes de inóculo, para todas as espécies de BYDV. Houve reação sorológica positiva para BYDV-PAV e MAV em todo o material testado (que são as espécies de BYDV predominantes na região Sul do Brasil), conforme relatado por Schons \& Dalbosco (1999). O trabalho foi conduzido na expectativa de que haveria uma infecção mista por BYDVPAV e MAV. Entretanto, ao realizar o DAS-ELISA na folha bandeira das plantas previamente expostas aos pulgões virulíferos, apenas BYDV-PAV foi detectado, constatandose que, por algum motivo, o BYDV- MAV não havia sido transmitido para nenhuma planta avaliada, ou a concentração viral ficou abaixo dos níveis detectáveis pelo teste.

Em todas as cultivares observou-se redução significativa na estatura das plantas na sub-parcela infectada pelo vírus. Nas plantas de trigo infectadas, houve redução na estatura das plantas, que variou de $12,5 \%$ na cultivar BRS 177 a 15,5\% na cultivar BRS Camboatá (Tabela 1). As cultivares BRS Angico e BRS Camboatá apresentaram menor estatura das plantas sadias quando comparadas às demais cultivares, diferença esta, que se manteve quando as plantas estavam infectadas pelo BYDV-PAV. As plantas sadias apresentaramse mais altas evidenciando que a infecção viral realmente reduziu o porte das plantas em todas as cultivares avaliadas. Resultados semelhantes foram encontrados por NicoliniTeixeira et al. (2006) em plantas de aveia infectadas com BYDV-PAV e BYDV-MAV cuja redução na estatura variou de $1,0 \%$ a $69,9 \%$. Os resultados encontrados indicam que o BYDV-PAV interfere, efetivamente, no crescimento das plantas de trigo.

Para os dados de peso da massa de matéria seca total, foram observadas diferenças significativas entre plantas infectadas e plantas sadias em todas as cultivares. Houve redução no peso da massa de matéria seca total de todas as plantas infectadas pelo BYDV-PAV (Tabela 1). A redução variou de $26,1 \%$ na cultivar BRS 177 a $51,4 \%$ na cultivar BRS 179, sendo que não houve diferença significativa entre

TABELA 1 - Danos causados pelo Barley yellow dwarf virus - PAV sobre a estatura e peso de massa de matéria seca de plantas de trigo

\begin{tabular}{|c|c|c|c|c|}
\hline \multirow[t]{2}{*}{ Cultivares } & \multicolumn{3}{|c|}{ Estatura média de 50 plantas $(\mathrm{cm})$} & \multirow{2}{*}{$\begin{array}{c}\text { Variação } \\
\text { percentual (\%) } \\
{[(\mathrm{S}-\mathrm{I}) / \mathrm{S}] * 100}\end{array}$} \\
\hline & Infectado & Sadio & Médias & \\
\hline BRS 179 & B 83,8 a & A $96,0 \mathrm{a}$ & 89,9 & 12,7 \\
\hline BRS 194 & B 82,4 a & A 96,1 a & 89,2 & 14,1 \\
\hline BRS Angico & B 59,6 b & A $68,8 \mathrm{~b}$ & 64,3 & 13,3 \\
\hline BRS 177 & B 81,4 a & A 93,1 a & 87,3 & 12,5 \\
\hline BRS Camboatá & B 58,8 b & A 69,6 b & 64,3 & 15,5 \\
\hline Médias & 73,2 & 84,8 & & \\
\hline \multicolumn{5}{|c|}{ C.V. parcela: $9,12 \%$} \\
\hline \multicolumn{5}{|c|}{ C.V. subparcela: $7,58 \%$} \\
\hline \multirow{2}{*}{ Cultivares } & \multicolumn{3}{|c|}{ Massa de matéria seca (g) } & $\begin{array}{c}\text { Variação } \\
\text { percentual (\%) }\end{array}$ \\
\hline & Infectado & Sadio & Médias & {$[(\mathrm{S}-\mathrm{I}) / \mathrm{S}] * 100$} \\
\hline BRS 179 & B 1,8 a & A 3,7 a & 2,8 & 52,7 \\
\hline BRS 194 & B 1,7 a & A $3,1 \mathrm{ab}$ & 2,4 & 47,0 \\
\hline BRS Angico & B 1,3 a & A $2,2 \mathrm{c}$ & 1,8 & 43,0 \\
\hline BRS 177 & B 1,7 a & A $2,3 \mathrm{c}$ & 2,0 & 26,5 \\
\hline BRS Camboatá & B 1,5 a & A $2,2 \mathrm{c}$ & 1,9 & 31,9 \\
\hline Médias & 1,6 & 2,3 & & \\
\hline \multicolumn{5}{|c|}{ C.V. parcela: $18,06 \%$} \\
\hline C.V. subparcela: & & & & \\
\hline
\end{tabular}

Médias seguidas da mesma letra minúscula na coluna e precedidas de mesma letra maiúscula na linha não diferem entre si pelo teste de Tukey a 5\% de significância. 
as cultivares quando infectadas. Já nas plantas sadias algumas cultivares apresentaram peso da massa de matéria seca total mais elevado que as demais, sugerindo, tratar-se de uma característica varietal. Quanto ao número de plantas por sub-parcela, não houve diferenças significativas entre plantas infectadas e plantas sadias, demonstrando que não houve, de modo geral, morte de plantas em função da infecção viral, contrariando Caetano (1972).

Dados referentes ao número médio de afilhos por planta evidenciam redução significativa no número de afilhos nas plantas infectadas com BYDV-PAV em relação às plantas sadias nas cultivares BRS 179 e BRS Angico (Tabela 2), estando de acordo com a observação feita por Caetano (1972), para o qual infecções de BYDV, que ocorrem precocemente, podem causar redução no desenvolvimento ou morte dos afilhos antes de completar o ciclo da cultura. Nas demais cultivares não houve diferenças significativas quanto ao número de afilhos em função da infecção viral. A variação percentual referente à diminuição do número de afilhos nas plantas infectadas pelo vírus variou de 8,3\% na cultivar BRS 177 a 26,6\% na cultivar BRS179. Resultados semelhantes em relação à diminuição do número de afilhos também foram observados por Nicolini-Teixeira et al. (2006) em plantas de aveia infectadas por BYDV-PAV e BYDV-MAV.

A análise referente ao número de espigas por planta

TABELA 2 - Danos causados pelo Barley yellow dwarf virus - PAV sobre o número de afilhos, de grãos por planta e peso de mil grãos de trigo

\begin{tabular}{|c|c|c|c|c|}
\hline \multirow{2}{*}{ Cultivares } & \multicolumn{3}{|c|}{ Número de afilhos/planta } & \multirow{2}{*}{$\begin{array}{c}\text { Variação } \\
\text { percentual (\%) } \\
{[(\mathrm{S}-\mathrm{I}) / \mathrm{S}] * 100}\end{array}$} \\
\hline & Infectado & Sadio & Médias & \\
\hline BRS 179 & B 1,1 a & A 1,5 a & 1,3 & 24,3 \\
\hline BRS194 & A 1,1 a & A 1,2 bc & 1,2 & 5,8 \\
\hline BRS Angico & B 1,2 a & A $1,5 \mathrm{ab}$ & 1,3 & 17,8 \\
\hline BRS 177 & A 1,1 a & A $1,2 \mathrm{c}$ & 1,2 & 4,2 \\
\hline BRS Camboatá & A 1,2 a & A $1,4 \mathrm{abc}$ & 1,3 & 8,1 \\
\hline Médias & 1,2 & 1,3 & & \\
\hline C. V. parcela: $13,8 \%$ & \multicolumn{3}{|c|}{ C.V. subparcela: $11,8 \%$} & \\
\hline \multirow{2}{*}{ Cultivares } & \multicolumn{3}{|c|}{ Número de grãos/planta } & $\begin{array}{c}\text { Variação } \\
\text { percentual (\%) }\end{array}$ \\
\hline & Infectado & Sadio & Médias & {$[(\mathrm{S}-\mathrm{I}) / \mathrm{S}] * 100$} \\
\hline BRS 179 & B $18,5 \mathrm{ab}$ & A 40,6 a & 29,6 & 54,3 \\
\hline BRS194 & B $13,4 \mathrm{~b}$ & A $24,7 \mathrm{c}$ & 19,1 & 45,9 \\
\hline BRS Angico & B $16,9 \mathrm{ab}$ & A 30,4 bc & 23,7 & 44,4 \\
\hline BRS 177 & B $18,5 \mathrm{ab}$ & A $36,5 \mathrm{ab}$ & 27,5 & 49,5 \\
\hline BRS Camboatá & B $20,6 \mathrm{a}$ & A $27,9 \mathrm{c}$ & 24,3 & 26,1 \\
\hline Médias & 17,6 & 32,0 & & \\
\hline C.V. parcela: $19,1 \%$ & C.V. subpa & $5,4 \%$ & & \\
\hline \multirow[t]{2}{*}{ Cultivares } & \multicolumn{3}{|c|}{ Massa de mil grãos (g) } & $\begin{array}{c}\text { Variação } \\
\text { percentual (\%) }\end{array}$ \\
\hline & Infectado & Sadio & Médias & {$[(\mathrm{S}-\mathrm{I}) / \mathrm{S}] * 100$} \\
\hline BRS 179 & B 47,9 a & A 64,2 a & 56,0 & 25,4 \\
\hline BRS194 & B $37,5 \mathrm{~b}$ & A $60,8 \mathrm{ab}$ & 49,1 & 38,4 \\
\hline BRS Angico & B $34,7 \mathrm{~b}$ & A 51,3 b & 43,0 & 32,3 \\
\hline BRS 177 & B $37,9 \mathrm{ab}$ & A 59,4 b & 48,7 & 36,3 \\
\hline BRS Camboatá & B $42,4 \mathrm{ab}$ & A $51,0 \mathrm{~b}$ & 46,7 & 16,9 \\
\hline Médias & 40,1 & 57,3 & & \\
\hline C.V. parcela: $14,4 \%$ & \multicolumn{3}{|c|}{ C.V. subparcela: $11,1 \%$} & \\
\hline
\end{tabular}

Médias seguidas da mesma letra minúscula na coluna e precedidas de mesma letra maiúscula na linha não diferem entre si pelo teste de Tukey a 5\% de significância. 
mostrou diferenças significativas entre plantas infectadas e plantas sadias (Tabela 2). Para o número médio de espigas por planta, melhores resultados foram observados nas plantas sadias. Isso representa dado esperado pois, de acordo com Caetano (1972), infecções por BYDV reduzem o número e tamanho das espigas. Variações percentuais na redução do número de espigas em função da infecção viral oscilaram de 8,3\% na cultivar BRS 194 a $21,4 \%$ na cultivar BRS 179 .

Houve diferenças significativas no número médio de grãos por planta (espiga principal + espiga secundária) (Tabela 2). Os melhores resultados foram observados nas plantas sadias, as quais apresentaram número mais elevado de grãos quando comparadas às infectadas, em todas as cultivares testadas.

Houve também interação entre cultivares versus condição (infectadas e sadias). Estes resultados eram também esperados, pois a infecção por BYDV promove a diminuição no número e em geral no peso dos grãos. Variações percentuais na redução do número médio de grãos em função da infecção pelo BYDV-PAV variaram de $26,1 \%$ na cultivar BRS Camboatá a 54,3\% na cultivar BRS 179.

Dados referentes à massa de mil grãos estão também apresentados na Tabela 2, evidenciando a diminuição da massa de mil grãos de $16,9 \%$ na cultivar BRS Camboatá a 38,4\% na cultivar BRS 194 nas plantas infectadas pelo BYDV-PAV. Já NicoloniTeixeira et al. (2006) observaram dados variáveis no peso de mil grãos em plantas de aveia infectadas pelo BYDVPAV e BYDV-MAV, sendo que em algumas cultivares houve peso mais elevado nas plantas infectadas, dado este também relatado por Caetano (1972), em que nas plantas infectadas a produção de grãos normalmente é prejudicada em número e peso, ocorrendo, porém casos em que a planta produz poucos grãos por espiga e nestas condições o peso dos grãos é relativamente mais elevado, este é o caso observado por Schons \& Dalbosco (1999), onde plantas de aveia infectadas pelo BYDV-PAV e BYDV-MAV não diferenciaram das plantas sadias com relação ao peso médio de mil grãos.

Com relação ao rendimento médio por hectare, houve diferenças significativas entre plantas infectadas com o BYDV-PAV quando comparadas ao controle sadio (Figura 1). Maior rendimento foi observado nas plantas sadias, que também apresentaram diferenças entre as cultivares, devido, provavelmente, a características varietais. Essas características não se expressaram nas plantas infectadas, dado bastante relevante, observandose que a cultivar com maior rendimento quando sadia (BRS 179), não foi a que mais rendeu quando infectada pelo vírus, que foi a cultivar BRS 177. Ao contrário, BRS 179 foi a cultivar que mais sofreu redução no rendimento $(60,8 \%)$ quando infectada pelo BYDV-PAV enquanto que a cultivar BRS Camboatá foi a que menos sofreu redução no rendimento $(34,2 \%)$.
A infecção natural por BYDV em aveia pode causar danos que variam de 3 a $52 \%$ (Schons et al., 1999). Em trigo, redução de até $63 \%$ na produtividade de grãos foi observada no ano de 1999 (Schons et al., 2000), dado este semelhante ao observado no presente estudo na cultivar BRS 179 (60,8\%).

Os dados apresentados na Figura 1 permitem observar que das cinco cultivares avaliadas, tiveram rendimento reduzido pela infecção com o BYDV-PAV, com variação percentual de 34,5 a $60,8 \%$. Dessa forma é possível inferir que as cinco cultivares apresentam diferentes níveis de suscetibilidade ao vírus.

Todos os parâmetros agronômicos analisados (característicasagronômicas e componentes dorendimento) foram afetados pela infecção por BYDV-PAV; o parâmetro agronômico mais afetado pela infecção pelo BYDV-PAV foi o rendimento médio por hectare; a cultivar BRS 179 foi mais afetada pela infecção, apresentando redução no peso médio da massa de matéria seca, número médio de afilhos por planta, número médio de espigas por planta, número médio de grãos por planta e rendimento $(\mathrm{kg} / \mathrm{ha})$; os resultados observados em relação a cultivar BRS 179 permitem classificá-lo como altamente suscetível ao BYDVPAV. Para o parâmetro massa de mil grãos a cultivar mais afetada pela infecção com o BYDV-PAV foi BRS 194; para o parâmetro estatura, a cultivar mais afetada pela infecção com o BYDV-PAV foi BRS Camboatá.

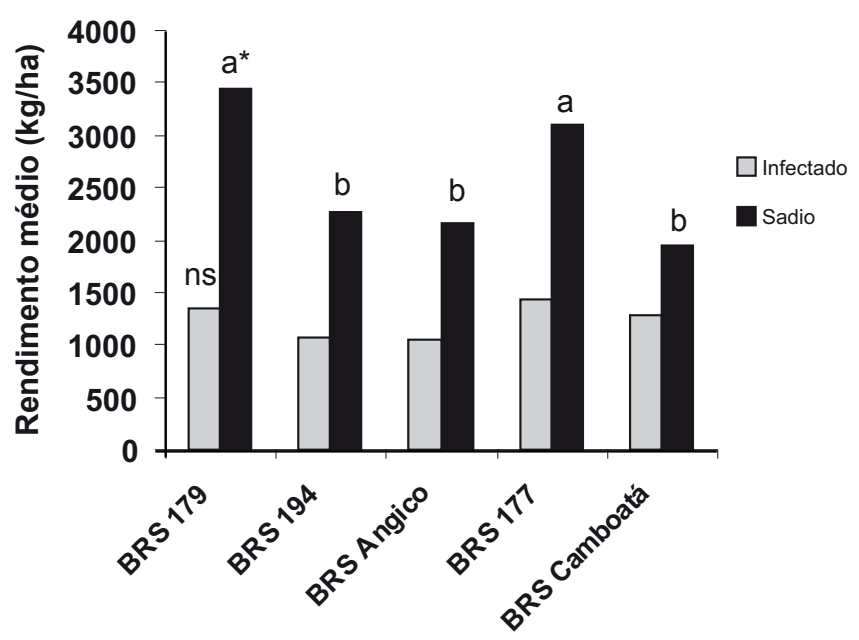

\section{Cultivares}

FIG. 1 - Rendimento médio por hectare de cultivares de trigo infectadas pelo Barley yellow dwarf virus - PAV e respectivos controles sadios.

*Médias seguidas da mesma letra não diferem entre si pelo teste de Tukey a 5\% de significância.

ns = não significativo. 


\section{AGRADECIMENTOS}

Ariane C. Lanzarini e Fernanda Nicolini-Teixeira agradecem à Coordenação de Aperfeiçoamento de Pessoal de Nível Superior - CAPES, Elaine Deuner à Fundação de Amparo à Pesquisa do Estado do Rio Grande do Sul Fapergs pela concessão de bolsa de estudo.

\section{REFERÊNCIAS BIBLIOGRÁFICAS}

BURNeTT, P.A., COMMEAU, A. \& QUALSET, C.O. Host plant tolerance or resistance for control of Barley yellow dwarf. In: D'arcy, C.J. \& Burnett, P.A. Barley yellow dwarf: 40 years of progress. Saint Paul MN. APS Press. 1995. pp. 321-343.

CAETANO, V.R. Estudo sobre o vírus do nanismo amarelo da cevada, em trigo, no Rio Grande do Sul. Tese de Doutorado. Piracicaba SP. Universidade de São Paulo - ESALQ. 1972.

CLARK, M.F. \& ADAMS, A.N. Characteristics of the microplate method of enzyme-linked immunosorbent assay for the detection of plant viruses. Journal General Virology 34:475-483. 1977.

GRAY, S.M. Plant virus proteins involved in natural vector transmission. Trends in Microbiology 4:259-264. 1996.

JENSEN, S.G. \& D'ARCY, C.L. Effects of barley yellow dwarf on host plants. In: D'Arcy, C.J. \& Burnett, P.A. (Eds.) Barley yellow dwarf: 40 years of progress. Saint Paul MN. APS Press. 1995. pp. 55-74.

LISTER, R.M. \& RANIERI, R. Distribution and economic importance of Barley yellow dwarf. In: D'Arcy, C.J. \& Burnett,
P.A. (Eds.) Barley yellow dwarf: 40 years of progress. Saint Paul MN. APS Press. 1995. pp. 29-53.

MILLER, W.A. \& ROSACHOVA L. Barley yellow dwarf viruses. Annual Review of Phytopathology 35:167-190. 1997.

NICOLINI-TEIXEIRA, F., SCHONS, J. COLOMBO, C.R. \& SOUZA, R. Avaliação do Barley yellow dwarf virus em genótipos de aveia. Revista Brasileira de Agrociência 12:423-427. 2006.

POWER, A.G., SEAMAN, A.J. \& GRAY S.M. Transmission of Barley yellow dwarf virus: inoculation access period and epidemiological implications. Phytopathology 81:545-548. 1991.

REUNIÃO DA COMISSÃO SUL-BRASILEIRA DE PESQUISA DE TRIGO. Indicações técnicas da Comissão Sul-Brasileira de Pesquisa de Trigo, trigo e triticale. Cruz Alta RS. Embrapa Trigo. 2005.

SCHONS, J. \& DALBOSCO, M. Identificação de estirpes do vírus do nanismo amarelo da cevada. Fitopatologia Brasileira 24(Supl.):359. 1999.

SCHONS, J., NICOLINI, F., KUYANA, S. R. SOARES, D.C. \& FLOSS, E.L. Danos causados pelo vírus do nanismo amarelo da cevada em 17 cultivares de aveia. Fitopatologia Brasileira 24(Supl.):360. 1999.

SCHONS, J., DALBOSCO, M., PANISSON, E., BOLLER, W. \& SOUZA, R. Danos causados pelo Barley yellow dwarf virus em trigo. Fitopatologia Brasileira 25(Supl.):634. 2000.

Van REGENMORTEL, M.H.V., FAUQUET, C.M., BISHOP, D.H.L., CARSTENS, E.B., ESTES, M.K., LEMON, S.M., MANILOFF, J., MAYO, M.A., MCGEOCH, D.J. PRINGLE, C.R. \& WICKNER, R.B. Virus Taxonomy - Seventh report of the Internacional Committee on Taxonomy of viruses. New York NY. Academic Press. 2000. 